\title{
Error Sensitivity to Initial Climate States in Pacific Decadal Hindcasts
}

\author{
Takashi Mochizuki ${ }^{1}$, Masahide Kimoto ${ }^{2}$, Yoshimitsu Chikamoto ${ }^{3}$, Masato Mori ${ }^{2}$, \\ Masahiro Watanabe ${ }^{2}$, and Masayoshi Ishii ${ }^{4}$ \\ ${ }^{1}$ Japan Agency for Marine-Earth Science and Technology, Yokohama, Japan \\ ${ }^{2}$ Atmosphere and Ocean Research Institute, the University of Tokyo, Kashiwa, Japan \\ ${ }^{3}$ International Pacific Research Center, University of Hawaii, Honolulu, USA \\ ${ }^{4}$ Meteorological Research Institute, Japan Meteorological Agency, Tsukuba, Japan
}

\begin{abstract}
We perform decadal hindcast experiments with initialization every year and assess sensitivity of the hindcasted errors to the errors in the initial climate states. The hindcasted sea surface temperature (SST) over the extratropical North Pacific shows significant impacts of initialization, yet the hindcasted indices of the Pacific decadal variability usually suffer from limited predictability. Our sensitivity analyses reveal that, in the decadal SST hindcasts over the extratropical North Pacific, the annual-todecadal errors of the Aleutian Low fluctuation before the time of starting hindcast experiments work as a major source of uncertainty through delayed responses of the ocean. As we directly assimilate only the ocean states to the atmosphere-ocean coupled model in initialization, the Aleutian Low fluctuation in the assimilation exhibits large errors even though the SST is well correlated with the observation. These assimilation errors in the Aleutian Low fluctuation are primarily due to the distorted responses of the extratropical atmosphere to the tropical SST changes in the model. A close examination indicates that the observed and assimilated Aleutian Lows are sensitive to the eastern and central equatorial SSTs, respectively. Toward further reducing uncertainty in the Pacific decadal hindcasts, therefore, it should be an effective way to raise quality of initial conditions for the extratropical atmosphere and the tropical atmosphere-ocean coupling.

(Citation: Mochizuki, T., M. Kimoto, Y. Chikamoto, M. Mori, M. Watanabe, and M. Ishii, 2014: Error sensitivity to initial climate states in Pacific decadal hindcasts. SOLA, 10, 39-44,
\end{abstract} doi:10.2151/sola.2014-009.)

\section{Introduction}

Climate prediction beyond interannual-scale variations provides to the world new and vital information for making political decisions to address the socioeconomic problems arising from imminent climate changes. Toward arriving at suitable decisions, the climate adaptation and mitigation communities require quantification and reduction of errors due to unavoidable uncertainty in climate predictions. In a centennial climate projection relevant to global warming, uncertainties in boundary conditions (i.e., scenario-based external forcing) and climate models (i.e., prediction systems) work as major sources of prediction errors. On the other hand, in a near-term (i.e., decadal) climate prediction which is one of the main subjects in Coupled Model Intercomparison Project Phase 5 (CMIP5) (Meehl et al. 2010, 2013), high quality of initial conditions is also responsible for raising the value of prediction information, since internal variability in the climate system definitely contributes to decadal climate changes (e.g., Murphy et al. 2004). Several modeling groups have demonstrated that initialization of atmosphere-ocean coupled states plays a decisive role in reducing the prediction errors relative to the global warm-

Corresponding author: Takashi Mochizuki, Japan Agency for Marine-Earth Science and Technology, 3173-25 Showa-machi Kanazawa-ku, Yokohama 236-0001, Japan. E-mail: motizuki@jamstec.go.jp. (C)2014, the Meteorological Society of Japan. ing projections (e.g., Smith et al. 2007; Keenlyside et al. 2008; Pohlmann et al. 2009; Mochizuki et al. 2010). Toward quantifying prediction uncertainty, statistical sensitivity of prediction errors to initial errors is useful information, since observational data to verify actual predictions are unavailable in practice at the time of making near-term climate prediction.

From another point of view, knowledge of the initial errors influencing the prediction errors, in addition to the error growth during the prediction, should give us an important insight into improving initial conditions toward more enhanced decadal predictability. Over the North Pacific, Mochizuki et al. (2010, 2012) have validated a skill in predicting the Pacific Decadal Oscillation (PDO) (Mantua et al. 1997) over the initial five years, by capturing significantly predictable changes as a part of the PDO in the ocean subsurface temperature. On the other hand, the comprehensive analyses for the CMIP5 decadal hindcasts have suggested that the decadal fluctuation of sea surface temperature (SST) exhibits limited predictability relative to other oceans even when applying initialization (Doblas-Reyes et al. 2011, 2013; Kim et al. 2012).

Here, we assess sensitivity of the errors in the decadal hindcasts to those in initial conditions in the Pacific. Since our initialization is based on data assimilation, we attempt to identify the assimilation errors that work as a major source of uncertainty in hindcasting the decadal SST variability. To do this, we build on our earlier experience of the decadal hindcast experiments officially performed for CMIP5 (Mochizuki et al. 2012; Chikamoto et al. 2013), by employing sets of 10 -year-long ensemble hindcasts with initialization every year. Ensembles of the initialized hindcasts every five years in the CMIP5 protocol (Taylor et al. 2012) are usually insufficient to evaluate the Pacific decadal predictability (Doblas-Reyes et al. 2013). Larger number of cases, as well as ensembles, of the hindcast experiments enables us to revisit the decadal predictability and explore the governing dynamical and physical processes with high statistical reliability.

\section{Ensembles of initialized decadal hindcast experi- ments}

The coupled atmosphere-ocean model adopted here is version 5 of Model for Interdisciplinary Research On Climate (MIROC5) with a medium resolution (Watanabe et al. 2010). The atmospheric component is T85 spectral model and has 40 levels, and the resolution of the ocean component is $1.4^{\circ}$ in longitude and $0.56^{\circ}-1.4^{\circ}$ in latitude and has 50 vertical levels. We use the historical data of radiative forcing (up to 2005) and Representative Concentration Pathways (RCP) 4.5 emission scenario (after 2006) in the CMIP5 protocol. The initialization approach is based on 2-member ensembles of anomaly data assimilation using MIROC5 and a gridded objective analysis as observation (Ishii and Kimoto 2009), as we officially performed for CMIP5 (Tatebe et al. 2012). In the data assimilation, the model ocean temperature and salinity anomalies in the upper $3000 \mathrm{~m}$ depth are forced to approach the observations using an incremental analysis update method (Bloom et al. 2006). We perform sets of 6-member ensembles of 10-year-long hindcast experiments with initialization every year after 1961. Three initial conditions are derived from each data assimilation run using a lagged average forecast method with 3-month intervals: 
For example, when a hindcast experiment starts from 1 January 1961, we define six initial conditions using two ensembles of the assimilation results on each of 1 July 1960, 1 October 1960 and 1 January 1961.

While anomaly initialization seems not to cause serious problems at the present stage of decadal climate prediction (Smith et al. 2013), it keeps model bias in climatology. For example, when compared to the observation, the oceanic fronts of the North Pacific (see below for detail) in MIROC5 climatology are about $70 \%$ in magnitude of the meridional SST gradient and their locations are shifted south about a few degrees due to the southward shifts of the surface westerlies in the atmospheric model (Watanabe et al. 2010). In addition, even though we perform anomaly initialization (i.e., assimilating anomalous values), we detect slight errors that display a specific spatiotemporal structure in the ocean surface and subsurface temperature hindcasts (Chikamoto et al. $2012 b$ ). These systematic errors are very small, when compared to the climate drift in hindcasts by full-field initialization (i.e., assimilating absolute values) primarily due to model bias in climatology. As in Mochizuki et al. (2012), we estimate these systematic errors as a function of lead time at each grid point in addition to the model bias in climatology. We analyze the modeled fields with them subtracted in this study. In the following sections, we mainly discuss the observed and modeled states averaged over hindcast years 2-5 (i.e., hindcast months 13-60), since our interests are directed into decadal fluctuations rather than the so-called global warming trend which largely influences hindcast skills beyond half a decade. Skills in the first year of the hindcast experiments should predominantly reflect the predictability of interannual variability such as the El Niño Southern Oscillation (ENSO) events.

\section{Skills in Pacific decadal hindcasts}

Potential predictability information obtained by examining signal-to-noise ratio of the Pacific decadal variability gives us an important insight into the key regions to be focused on, when verifying predictive skills and impacts of initialization in decadal hindcasts. In the ocean subsurface temperature (vertically-averaged ocean temperature between 100-400 m depth; VAT), for example, numerical studies have detected potential predictability over the extratropical oceanic fronts (Sugiura et al. 2009; Teng and Branstator 2011; Branstator and Teng 2012): The subarctic and eastern subtropical fronts, defined here as $\left(38^{\circ} \mathrm{N}-48^{\circ} \mathrm{N}, 160^{\circ} \mathrm{E}-160^{\circ} \mathrm{W}\right)$ and $\left(24^{\circ} \mathrm{N}-34^{\circ} \mathrm{N}, 160^{\circ} \mathrm{W}-180^{\circ}\right)$, respectively (see rectangles A and $\mathrm{E}$ in Fig. 1). In addition, Boer and Lambert (2008) and Boer (2011) have indicated the potential predictability of internallygenerated SST changes north of $35^{\circ} \mathrm{N}$ on decadal timescales.

Anomaly correlation coefficients (ACCs) and reduction rate of root-mean-squared errors (RMSEs) relative to the historical simulations without initialization at each grid point are useful to illustrate quality (i.e., skill) of our hindcasts and impacts of initialization, respectively (Fig. 1). As shown in Mochizuki et al. (2010, 2012), our initialization works to reduce the hindcasted VAT errors particularly around the eastern and western (i.e., $20^{\circ} \mathrm{N}-30^{\circ} \mathrm{N}$, $135^{\circ} \mathrm{E}-175^{\circ} \mathrm{E}$; rectangle W) subtropical fronts (Fig. 1c) where the ACCs significantly validate the predictive skills (Fig. 1a). Over the subarctic front, on the other hand, the significant correlation and the RMSE reduction are found only in limited areas. For the first and second empirical orthogonal functions (EOFs) of the North Pacific VAT, the hindcasted time coefficients represent favorable comparison with the observations (Figs. 2a, c), largely due to high quality of the VAT hindcasts over the subtropical fronts. The first EOF corresponds to the PDO and displays large fluctuations over the eastern subtropical front as well as around $40^{\circ} \mathrm{N}, 160^{\circ} \mathrm{W}$. The second EOF includes decadal variation of the western subtropical front and represents the North Pacific Gyre Oscillation (NPGO) (Di Lorenzo et al. 2008), having also been referred to as the Victoria mode (Bond et al. 2003). The hindcasted ACCs of the VAT-derived PDO and NPGO indices (i.e., time coefficients of the first and second EOFs) indicate that the initialized hindcasts are superior to the so-called persistence prediction with keeping an initial condition (i.e., an assimilated state) as it is. These ACC values are also larger than those of the persistence prediction with keeping an observed state rather than the assimilation, which are calculated as the autocorrelation coefficients of the 4-year mean observation with a lag of 5-years.

Values of SST rather than VAT are commonly used to define the PDO and NPGO indices. Unlike the VAT-derived indices, the SST-derived indices show low predictability in our hindcasts (Fig. 2b, d), as in a CMIP5 multi-model analysis (Kim et al. 2012), probably due to low skills over the subarctic front (Fig. 1b) where
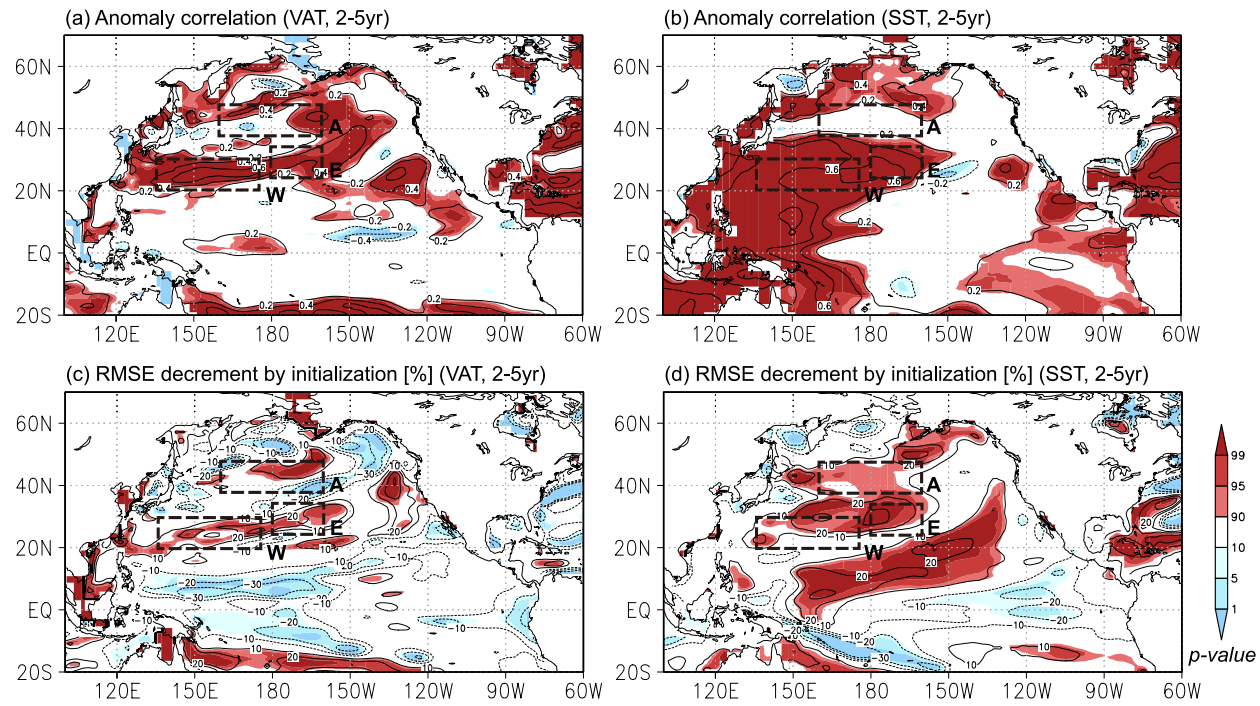

Fig. 1. (a) Anomaly correlation coefficients of the ensemble mean of 2-5 yr hindcasted VAT with the observation at each grid point. Shaded are the areas where the coefficient is statistically significant at a $90 \%$ confidence level in Student t-test using bootstrap approach by random resampling with replacement (e.g., Mochizuki et al. 2010). Three rectangles A, E and W represent the subarctic front $\left(38^{\circ} \mathrm{N}-48^{\circ} \mathrm{N}, 160^{\circ} \mathrm{E}-160^{\circ} \mathrm{W}\right)$, which is defined as a key region for error sensitivity analysis in this study, and the eastern $\left(24^{\circ} \mathrm{N}-34^{\circ} \mathrm{N}, 160^{\circ} \mathrm{W}-180^{\circ}\right)$ and western $\left(20^{\circ} \mathrm{N}-30^{\circ} \mathrm{N}, 135^{\circ} \mathrm{E}-175^{\circ} \mathrm{E}\right)$ subtropical fronts $(\mathrm{c} . f$, Kobashi et al. 2006), respectively. (b) The same as in panel a, except for SST. (c) Reduction rates of RMSEs of VAT ensemble means due to initialization at each grid point. Values are calculated as ratios of RMSEs of the initialized decadal hindcasts for hindcast years $2-5$ and those of the historical simulations without initialization (i.e., so-called global warming simulations). Shaded are the areas where the rate is significant at a $90 \%$ confidence level in bootstrap approach. (d) The same as in panel c, except for SST. 

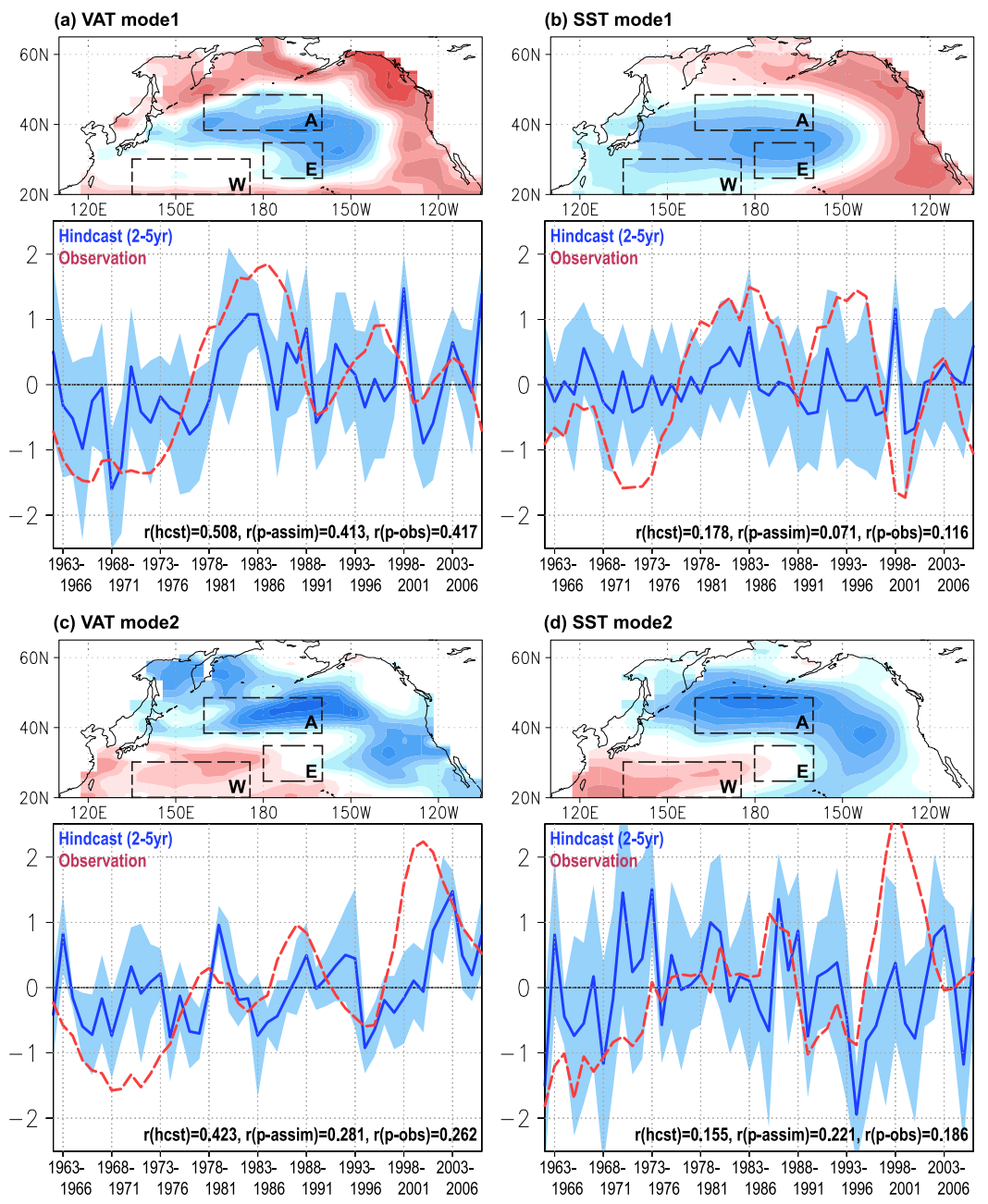

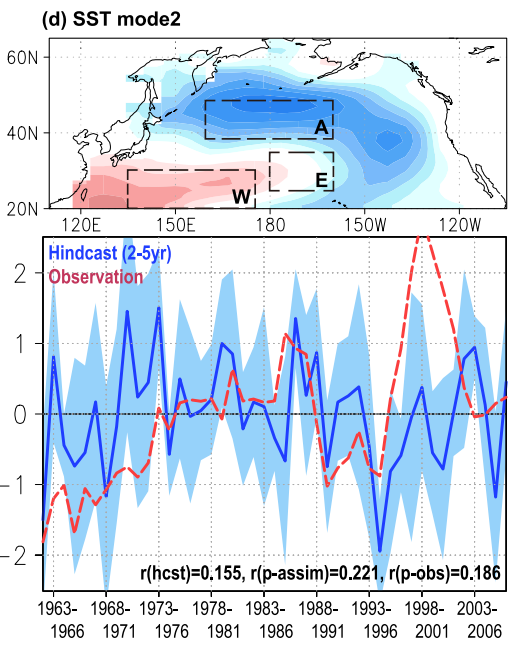

Fig. 2. (a) The leading empirical orthogonal function (EOF) of the observed VAT in the North Pacific (north of $20^{\circ} \mathrm{N}$ ) during 1949-2008. Time coefficients are defined as the regressions of the ensemble mean of 2-5 yr hindcasts onto the EOF (blue line) and the corresponding values of the observation (Ishii and Kimoto 2009) (red line). Plotted values are normalized using the observed standard deviation. Blue shades represent the ensemble spreads of the hindcasts. Values of $r(h c s t), r(p$-assim) and $r(p$-obs) represent the anomaly correlations, with the observation over hindcast years $2-5$, of the initialized hindcasts and the so-called persistence predictions with keeping the initial states of the assimilation and the observation, respectively. (b) The same as in panel a, except for SST. Lower panels are the same as in upper panels, except for the second EOFs and the normalized regressions of (c) VAT and (d) SST, respectively.
SST change can contribute largely to the NPGO and possibly to the PDO (Figs. 2b, d). The insignificant skills east of $150^{\circ} \mathrm{W}$ may help to degrade the hindcast quality of these indices (Fig. 1b). On the other hand, it is noteworthy that the significant reduction of RMSE is simulated around the subarctic front (Fig. 1d), different from a CMIP5 multi-model analysis (Doblas-Reyes et al. 2013). The initialization significantly works to realize the potential predictability of internally-generated SST changes (Boer and Lambert 2008; Boer 2011), while it insufficiently raises the hindcast quality which still represents smaller ACC value than a $90 \%$ significance level at this stage. These results suggest that, toward achieving full potential of decadal SST predictability, it should be a hopeful approach to understand sources of hindcast SST errors over the subarctic front. While Guemas et al. (2012) have suggested that the poorly predictive skill for the warming events in the 1960 s is the major reason for the low predictive skill of the PDO, large errors of the PDO indices are not limited in the 1960s in our hindcasts (Fig. 2b).

Note that, whereas the ACC of the hindcasted SST is very large over the western subtropical Pacific (i.e., including the subtropical fronts) (Fig. 1b), it insufficiently contributes to yield the hindcast skills for the PDO and NPGO indices. This high correlation is primarily due to long predictability of externally-forced variability (Mochizuki et al. 2012) and the initialization hardly reduces the hindcasted RMSE except for the northern part of the subtropical fronts (Fig. 1d). While the stepwise warming originated in the North Atlantic in the 1990s may also contribute to the high ACC (Chikamoto et al. 2012a), it does not sufficiently raise the predictive skills of the PDO and NPGO indices in a statistical sense.

\section{Initial errors degrading skills of the Pacific decadal hindcasts}

The PDO and NPGO indices of 2-5 yr hindcasts yield decadalscale errors that depend little on a specific phase of oscillations (Fig. 2), in addition to high frequency noise partly due to the small numbers of ensembles and excessively strong inertia of the model in interannual fluctuations (e.g., 1997-98 El Niño event). We assess linear sensitivity of the hindcasted errors to the initial climate states, by calculating correlation coefficients between the hindcasted and assimilated errors. In particular, we focus on the hindcasted SST over the subarctic front, as described above, where the predictive skill of SST is still quite low (Fig. 1b) but the potential predictability has been detected on decadal timescales (Boer and Lambert 2008; Boer 2011) and the significant impact of initialization is practically validated by our prediction system (Fig. 1d).

Figure 3 shows correlation maps of 4-year and 1-year mean errors of the assimilation (i.e., differences between the assimilation and the observation) just before the time of starting hindcast runs, with those of the ensemble-mean SST error in 2-5 yr hindcasts averaged over the subarctic front. The hindcasted errors in the subarctic front are closely related to the SST errors over the central North Pacific both in 4-year and 1-year means of the assimilation (Figs. 3a, b). In the assimilation runs, the wintertime (i.e., during November-March) sea level pressure (SLP) errors in the extratropics work to form these SST errors (Figs. 3e, f) through heat flux changes at the sea surface. In the tropics, in addition, the SST and SLP errors display significantly positive and negative correlations, respectively, implying possible contribution 

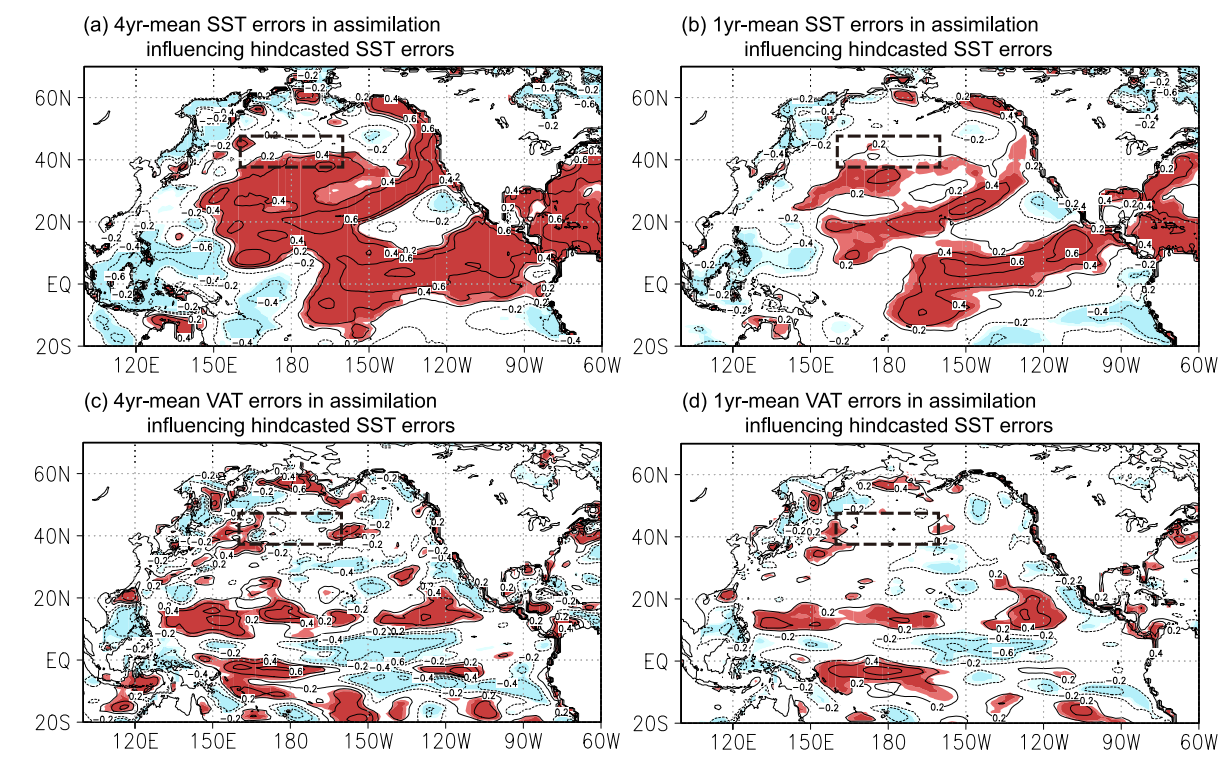

(d) 1yr-mean VAT errors in assimilation

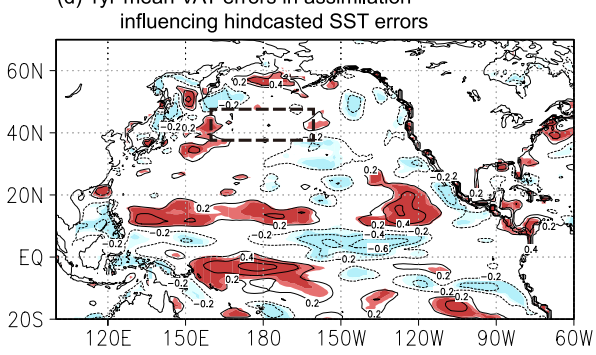

(e) 4yr-mean SLP errors in assimilation
influencing hindcasted SST errors

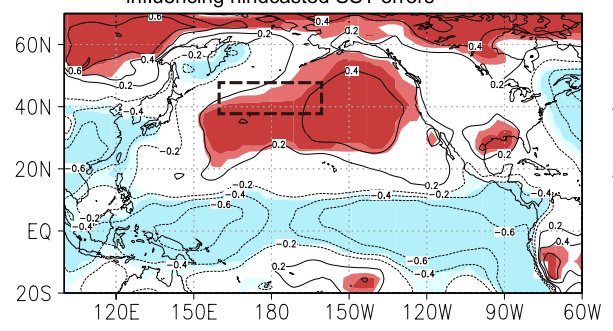

(f) $1 \mathrm{yr}$-mean SLP errors in assimilation

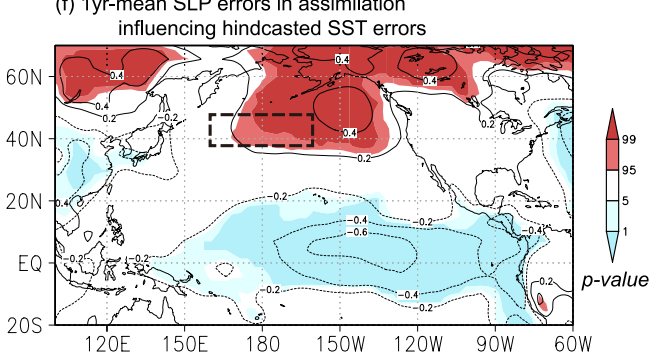

Fig. 3. Correlation maps of (a) 4-year and (b) 1-year mean SST errors in the assimilation just before start date of hindcast experiments, with the SST errors in the $2-5 \mathrm{yr}$ hindcasts over the subarctic front (regtangles). Shaded are the areas where the correlation coefficient is significant at a $95 \%$ confidence level in bootstrap approach. Middle panels are the same as in top panels, except for correlations of the VAT errors in the assimilation. Bottom panels are the same as in top panels, except for correlations of the wintertime SLP errors in the assimilation, which are calculated using NCEP reanalysis as the observation.

from the tropical SST. The assimilated VAT errors have little contribution even over the upstream area in the ocean gyre circulation (Figs. 3c, d).

Actually, in our decadal hindcasts, the initial errors of the Aleutian Low work to yield errors in the SST hindcasts over the subarctic front as well as the eastern subtropical front and the Gulf of Alaska (Fig. 4). The hindcasted SST errors are well correlated with the 4-year means of assimilation errors of the wintertime North Pacific Index (NPI) (Fig. 4a), defined as an area-averaged SLP over $30^{\circ} \mathrm{N}-65^{\circ} \mathrm{N}, 160^{\circ} \mathrm{E}-140^{\circ} \mathrm{W}$ (Trenberth and Hurrell 1994). Recent studies have indicated that the Aleutian Low fluctuations control slow changes of strength and/or location of the subarctic front on decadal timescales (Taguchi et al. 2012) through delayed influence of the oceanic Rossby wave adjustment (Kwon and Deser 2007; Qiu et al. 2007; Ceballos et al. 2009). The assimilated NPI errors in the preceding winter of starting hindcast runs (Fig. 4b) lead to a similar correlation map to Fig. 4a, also suggesting contribution of delayed (baroclinic and/or barotropic) responses of the extratropical ocean to an SLP anomaly in a specific winter (Vimont 2005; Newman 2007; Chhak et al. 2009). Note that, when compared to the 4-year means of the wintertime NPI errors, this contribution to the hindcasted SST errors is slightly small (see hatches in Fig. 4).

These NPI errors in the assimilation are not directly due to the tropical SST errors but largely due to distorted responses of the extratropical atmosphere to the tropical SST changes in the model (Fig. 5). The assimilated NPI represents very different time series from the observation (correlation coefficient is -0.04) (Figs. 5a, b). The observed and assimilated NPIs are strongly correlated with the NINO3 and NINO4 SSTs, respectively. The SSTs simultaneously correlated with NPIs also display different spatial patterns (Figs. 5c, d). In the observations, the anomaly correlation of SST
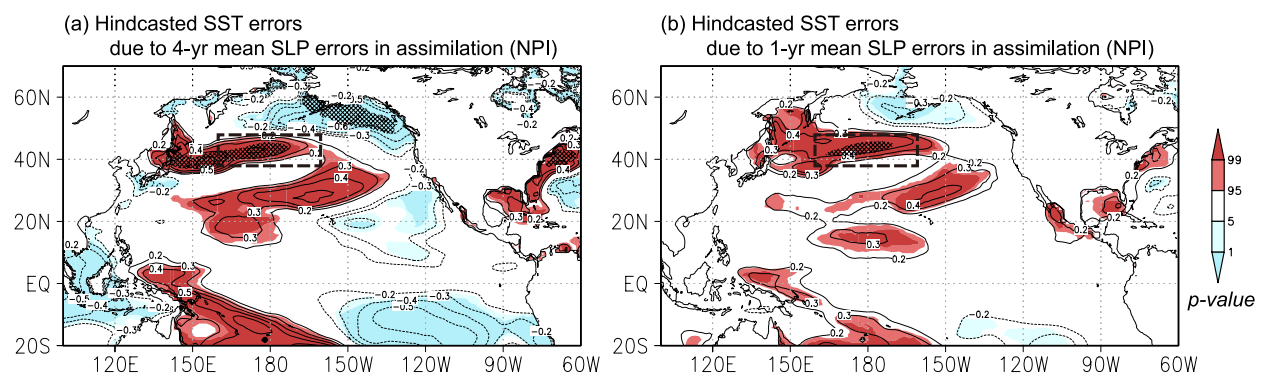

Fig. 4. Correlation maps of ensemble-mean errors in 2-5 yr SST hindcasts, with those in the wintertime NPI assimilation over the preceding (a) 4-years and (b) 1-year of starting hindcast runs. Shaded are the areas where the correlation coefficient is significant at a $95 \%$ confidence level in bootstrap approach. Hatches represent the areas where the SST error linearly regressed on the normalized NPI error is larger than $0.2^{\circ} \mathrm{C}$ in magnitude. 
(a) NPI, NINO3 SST in observation

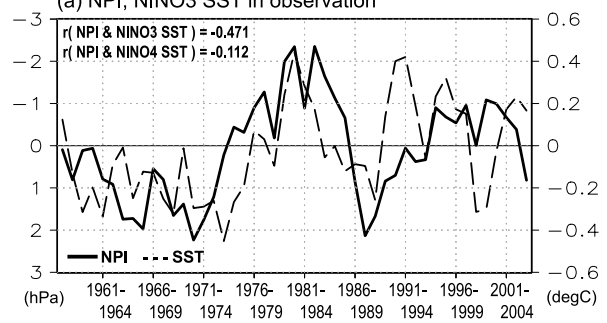

(c) Anomaly correlation (SST to NPI) in observation

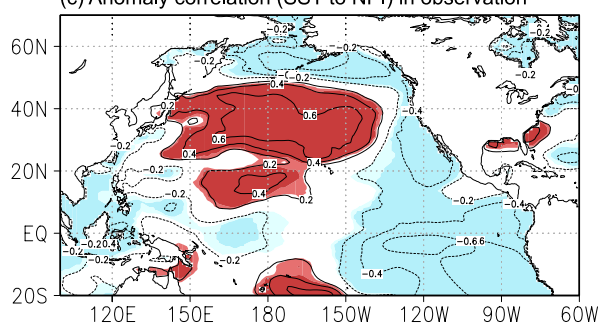

(b) NPI, NINO4 SST in assimilation

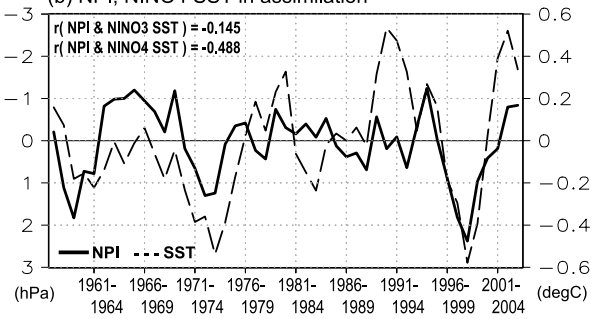

(d) Anomaly correlation (SST to NPI) in assimilation

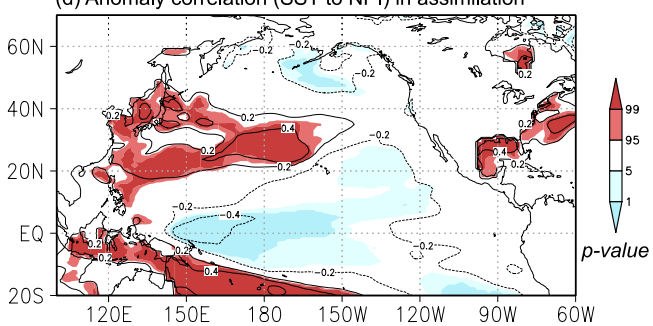

Fig. 5. (a) The time series of 4-year means of the wintertime NPI derived from the NCEP reanalysis and the observed NINO3 SST (i.e., SST averaged over $\left.5^{\circ} \mathrm{S}-5^{\circ} \mathrm{N}, 90^{\circ} \mathrm{W}-150^{\circ} \mathrm{W}\right)$. Values of $r$ represent the anomaly correlations of the NPI with the NINO SSTs (i.e., NINO3 SST or NINO4 SST). (b) The same as in panel a, except for the NPI and NINO4 SST (i.e., SST averaged over $5^{\circ} \mathrm{S}-5^{\circ} \mathrm{N}, 160^{\circ} \mathrm{E}-150^{\circ} \mathrm{W}$ ) in the assimilation. (c) Correlation map of the SST observation with the NPI reanalysis. Shaded are the areas where the correlation coefficient is significant at a $95 \%$ confidence level in bootstrap approach. (d) The same as in panel c, except for using the SST and SLP assimilations.

represents a negative PDO-like spatial pattern (Fig. 5c), suggesting that the Aleutian Low changes are controlled by the eastern tropical Pacific SST. In the assimilation, on the other hand, the negative correlation of SST is found over the central equatorial Pacific (i.e., around the date line) (Fig. 5d). These results help us to interpret the error sensitivity maps in Fig. 3. When the NINO3 SST is observed higher than the climatology, for example, the Aleutian Low is enhanced (Fig. 5c) and the NPI shows a negative anomaly (Fig. 5a). Even though the assimilation simulates a positive NINO3 SST anomaly as observed, the Aleutian Low in the assimilation is barely enhanced in a statistical sense due to quite a modest influence from the NINO3 SST in the model (Figs. $5 \mathrm{~b}, \mathrm{~d})$. Consequently, the Aleutian Low is excessively weak and accompanied by a high SST around its southern edge (Fig. 5d). Similarly, the error sensitivity maps of the extratropical SLP and SST display positive ACCs around $40^{\circ} \mathrm{N}$ and $30^{\circ} \mathrm{N}$, respectively (Figs. 3a, e). In the tropics, the error sensitivity maps show the negative ACC in SLP (Fig. 3e) together with the positive ACC in SST (Fig. 3a). In fact, while the NINO3 SST fluctuation is directly assimilated in our experiment, the assimilation usually simulates the realistic phase of oscillation with larger amplitude (standard deviation is $0.29^{\circ} \mathrm{C}$ ) than the observation (standard deviation is $0.23^{\circ} \mathrm{C}$ ).

\section{Summary and discussion}

We have performed initialized decadal hindcast experiments starting every year and have assessed sensitivity of the hindcasted errors to the assimilated errors. When focusing on decadal SST variations over the subarctic front, our sensitivity analyses have revealed that the assimilation errors in the annual-to-decadal Aleutian Low fluctuation work as a major source of uncertainty through delayed response of the ocean. These assimilation errors in the Aleutian Low fluctuation are primarily due to the distorted responses of the extratropical atmosphere to the tropical SST changes in the model. The observed and assimilated Aleutian Low fluctuations are sensitive to the SST changes over the eastern and central equatorial Pacific, respectively.

Schneider and Cornuelle (2005) and Newman et al. (2003) have indicated that the observed PDO signals in the extratropical SST are yielded by a combination of three independent processes in comparable levels: Decadal memory through the extratropical ocean dynamics, remote forcing from the tropical SST and stochastic forcing due to internal dynamics of the midlatitude atmosphere. In the hindcast experiments, the well predictive skill in the VAT-derived PDO index is demonstrated primarily due to the extratropical ocean dynamics (Mochizuki et al. 2012). On the other hand, all of the three processes can contribute to the hindcast errors of SST and VAT. In particular, when focusing on the initialization as a pressing concern in decadal climate prediction, we have revealed that the remote forcing from the tropical SST plays a major role in yielding the extratropical SST errors by controlling the quality of the modeled Aleutian Low. While the atmosphere does not have decadal memory by itself, the ocean errors that are dynamically excited by the annual-to-decadal Aleutian Low errors in assimilation (e.g., errors in sea surface height) significantly exert delayed influences on 2-5 yr hindcasts. In other words, towards further improving Pacific decadal predictability, the key issues in initialization is quality of the extratropical atmosphere and the tropical atmosphere-ocean coupling (i.e., the annual-to-decadal Aleutian Low fluctuations and remote influences from the tropical SST), as well as in a level of performance of the climate model.

\section{Acknowledgements.}

The authors wish to thank Mr. H. Kanai and Drs. T. Nishimura, K. Ogochi, H. Tatebe, T. Yokohata, Y. Komuro and T. T. Sakamoto for their supports in performing the experiments. This work is supported by the SOUSEI program and the Grant-in-Aid for Young Scientists B-23740362.

\section{References}

Bloom, S. C., L. Takacs, A. M. da Silva, and D. Ledvina, 1996: Data assimilation using Incremental Analysis Updates. Mon. Wea. Rev., 124, 1256-1271.

Boer, G. J., 2011: Decadal potential predictability of twenty-first century climate. Clim. Dyn., 36, 1119-1133, doi:10.1007/ s00382-010-0747-9.

Boer, G. J., and S. J. Lambert, 2008: Multi-model decadal potential predictability of precipitation and temperature. Geophys. Res. Lett., 35, L05706, doi:10.1029/2008GL033234.

Bond, N. A., J. E. Overland, M. Spillane, and P. Stabeno, 2003: Recent shifts in the state of the North Pacific. Geophys. Res. 
Lett., 30, 2183, doi:10.1029/2003GL018597.

Branstator, G., and H. Teng, 2012: Potential impact of initialization on decadal predictions as assessed for CMIP5 models. Geophys. Res. Lett., 39, L12703, doi:10.1029/2012GL051974.

Ceballos, L. I., E. Di Lorenzo, C. D. Hoyos, N. Schneider, and B. Taguchi, 2009: North Pacific gyre oscillation synchronizes climate fluctuations in the eastern and western boundary systems. J. Climate, 22, 5163-5174.

Chhak, K. C., E. Di Lorenzo, N. Schneider, and P. F. Cummins, 2009: Forcing of low-frequency ocean variability in the northeast Pacific. J. Climate, 22, 1255-1276.

Chikamoto, Y., M. Kimoto, M. Watanabe, M. Ishii, and T. Mochizuki, 2012a: Relationship between the Pacific and Atlantic stepwise climate change during the 1990. Geophys. Res. Lett., 39, L21710, doi:10.1029/2012GL053901.

Chikamoto, Y., M. Kimoto, M. Ishii, M. Watanabe, T. Mochizuki, H. Tatebe, T. T. Sakamoto, Y. Komuro, H. Shiogama, M. Mori, S. Yasunaka, Y. Imada, H. Koyama, M. Nozu, and F.-F. Jin, 2012b: Predictability of a stepwise shift in Pacific climate during the late 1990 s in hindcast experiments using MIROC. J. Meteor. Soc. Japan, 90A, 1-21.

Chikamoto, Y., M. Kimoto, M. Ishii, T. Mochizuki, T. T. Sakamoto, H. Tatebe, Y. Komuro, M. Watanabe, T. Nozawa, H. Shiogama, M. Mori, S. Yasunaka, and Y. Imada, 2013: An overview of decadal climate predictability in a multi-model ensemble by climate model MIROC. Clim. Dyn., 40, 12011222.

Di Lorenzo, E., N. Schneider, K. M. Cobb, P. J. S. Franks, K. Chhak, A. J. Miller, J. C. McWilliams, S. J. Bograd, H. Arango, E. Curchitser, T. M. Powell, and P. Riviere, 2008: North Pacific Gyre Oscillation links ocean climate and ecosystem change. Geophys. Res. Lett., 35, doi:10.1029/2007GL 032838.

Doblas-Reyes, F. J., M. A. Balmaseda, A. Weisheimer, and T. N. Palmer, 2011: Decadal climate prediction with the ECMWF coupled forecast system: Impact of ocean observations. $J$. Geophys. Res., 116, D19111, doi:10.1029/2010JD015394.

Doblas-Reyes, F. J., I. Andreu-Burillo, Y. Chikamoto, J. GarciaSerrano, V. Guemas, M. Kimoto, T. Mochizuki, L. R. L. Rodrigues, and G. J. van Oldenborgh, 2013: Initialized nearterm regional climate change prediction. Nature Comms., $\mathbf{4}$, 1715, doi:10.1038/ncomms2704.

Guemas, V., F. J. Doblas-Reyes, F. Lienert, Y. Soufflet, and H. $\mathrm{Du}, 2012$ : Identifying the causes for the low decadal climate forecast skill over the North Pacific. J. Geophys. Res., 117, D20111, doi:10.1029/2012JD018004.

Ishii, M., and M. Kimoto, 2009: Reevaluation of historical ocean heat content variations with time-varying XBT and MBT depth bias corrections. J. Oceanogr., 65, 287-299.

Keenlyside, N. S., M. Latif, J. Jungclaus, L. Kornblueh, and E. Roeckner, 2008: Advancing decadal-scale climate prediction in the North Atlantic sector. Nature, 453, 84-88.

Kim, H., P. Webster, and J. Curry, 2012: Evaluation of short-term climate change prediction in multi-model cmip5 decadal hindcasts. Geophys. Res. Lett., 39, L10701, doi:10. 1029/ 2012 GL051644.

Kobashi, F., H. Mitsudera, and S.-P. Xie, 2006: Three subtropical fronts in the North Pacific: observational evidence for mode water-induced subsurface frontogenesis. J. Geophys. Res., 111, C09033, doi:10.1029/2006JC003479.

Kwon, Y. O., and C. Deser, 2007: North Pacific decadal variability in the Community Climate System Model version 2. J. Climate, 20, 2416-2433.

Mantua, N. J., S. R. Hare, Y. Zhang, J. M. Wallace, and R. C. Francis, 1997: A Pacific interdecadal climate oscillation with impacts on salmon production. Bull. Amer. Meteor. Soc., 78, 1069-1079.

Meehl, G. A., A. Hu, and C. Tebaldi, 2010: Decadal prediction in the Pacific region. J. Climate, 23, 2959-2973.

Meehl, G. A., and co-authors, 2013: Decadal climate prediction: An update from the trenches. Bull. Amer. Meteor. Soc., 94, doi:10.1175/BAMS-D-12-00241.1.
Mochizuki, T., M. Ishii, M. Kimoto, Y. Chikamoto, M. Watanabe, T. Nozawa, T. T. Sakamoto, H. Shiogama, T. Awaji, N. Sugiura, T. Toyoda, S. Yasunaka, H. Tatebe, and M. Mori, 2010: Pacific decadal oscillation hindcasts relevant to near-term climate prediction. Proc. Natl. Acad. Sci. USA, 107, 18331837, doi:10.1073/pnas.0906531107.

Mochizuki, T., Y. Chikamoto, M. Kimoto, M. Ishii, H. Tatebe, Y. Komuro, T. T. Sakamoto, M. Watanabe, and M. Mori, 2012: Decadal prediction using a recent series of MIROC global climate models. J. Meteor. Soc. Japan, 90A, 373-383.

Murphy, J. M., D. M. Sexton, D. N. Barnett, G. S. Jones, M. J. Webb, M. Collins, and D. A. Stainforth, 2004: Quantification of modelling uncertainties in a large ensemble of climate change simulations. Nature, 430, 768-772.

Newman, M., 2007: Interannual to decadal predictability of tropical and North Pacific sea surface temperatures. J. Climate, 20, 2333-2356.

Newman, M., G. P. Compo, and M. A. Alexander, 2003: ENSO-forced variability of the Pacific Decadal Oscillation. $J$. Climate, 16, 3853-3857.

van Oldenborgh, G. J., F. J. Doblas-Reyes, B. Wouters, and W. Hazeleger, 2012: Decadal prediction skill in a multi-model ensemble. Clim. Dyn., 38, 1263-1280.

Pohlmann, H., J. H. Jungclaus, A. Köhl, D. Stammer, and J. Marotzke, 2009: Initializing decadal climate predictions with the GECCO oceanic synthesis: Effect on the North Atlantic. J. Climate, 22, 3926-3938.

Qiu, B., N. Schneider, and S. Chen, 2007: Coupled decadal variability in the North Pacific: An observationally constrained idealized model. J. Climate, 20, 3602-3620.

Smith, D. M., S. Cusack, A. W. Colman, C. K. Folland, G. R. Harris, and J. M. Murphy, 2007: Improved surface temperature prediction for the coming decade from a global climate model. Science, 317, 796-799.

Smith, D. M., R. Eade, and H. Pohlmann, 2013: A comparison of full-field and anomaly initialization for seasonal to decadal climate prediction. Clim. Dyn., 41, 3325-3338.

Schneider, N., and B. D. Cornuelle, 2005: The forcing of the Pacific Decadal Oscillation. J. Climate, 18, 4355-4373.

Sugiura, N., T. Awaji, S. Masuda, T. Toyoda, H. Igarashi, Y. Ishikawa, M. Ishii, and M. Kimoto, 2009: The potential for decadal predictability in the North Pacific region. Geophys. Res. Lett., 36, L20701, doi:10.1029/2009GL039787.

Tatebe, H., M. Ishii, T. Mochizuki, Y. Chikamoto, T. T. Sakamoto, Y. Komuro, M. Mori, S. Yasunaka, M. Watanabe, K. Ogochi, T. Suzuki, T. Nishimura, and M. Kimoto, 2012: Initialization of the climate model MIROC for decadal predictions by assimilating ocean hydrography. J. Meteor. Soc. Japan, 90A, 275-294.

Taylor, K. E., R. J. Stouffer, and G. A. Meehl, 2012: An overview of CMIP5 and the experiment design. Bull. Amer. Meteor. Soc., 92, 485-498.

Teng, H., and G. Branstator, 2011: Initial-value predictability of prominent modes of North Pacific subsurface temperature in a CGCM. Clim. Dyn., 36, 1813-1834.

Trenberth, K. E., and J. W. Hurrell, 1994: Decadal atmosphereocean variations in the Pacific. Clim. Dyn., 9, 303-319.

Vimont, D. J., 2005: The contribution of the interannual ENSO cycle to the spatial pattern of ENSO-like decadal variability. J. Climate, 18, 2080-2092.

Watanabe, M., T. Suzuki, R. O'ishi, Y. Komuro, S. Watanabe, S. Emori, T. Takemura, M. Chikira, T. Ogura, M. Sekiguchi, K. Takata, D. Yamazaki, T. Yokohata, T. Nozawa, H. Hasumi, H. Tatebe, and M. Kimoto, 2010: Improved climate simulation by MIROC5: Mean states, variability, and climate sensitivity. J. Climate, 23, 6312-6335.

Manuscript received 25 November 2013, accepted 20 February 2014 SOLA: http://www.jstage.jst.go.jp/browse/sola/ 